\title{
Methicillin-resistant Staphylococcus aureus: A public health issue with economic consequences
}

\author{
Mireille Goetghebeur PhD ${ }^{1}$, Pierre-Alexandre Landry $\mathrm{PhD}^{1}$, Donald Han ${ }^{2}$, Colin Vicente $\mathrm{MSc}^{2}$
}

\author{
M Goetghebeur, P-A Landry, D Han, C Vicente. Methicillin- \\ resistant Staphylococcus aureus: A public health issue with \\ economic consequences. Can J Infect Dis Med Microbiol \\ 2006;18(1):27-34.
}

BACKGROUND: Methicillin-resistant Staphylococcus aureus (MRSA) has become endemic worldwide in hospitals, and communityassociated MRSA is spreading into the community at large.

OBJECTIVES: To estimate the current cost of MRSA in Canada and to assess the magnitude of this public health issue.

METHODS: An extensive review of the literature was conducted to gather epidemiology, health care resource utilization and cost data for MRSA in Canadian settings. The current MRSA burden was estimated using available cost data and the most recent epidemiology data.

RESULTS: The rate of MRSA in Canadian hospitals increased from 0.46 to 5.90 per 1000 admissions between 1995 and 2004, while community-associated MRSA continued to spread into the community. Patients harbouring MRSA required prolonged hospitalization (average 26 days of isolation per patient), special control measures, expensive treatments and extensive surveillance. Total cost per infected MRSA patient averaged $\$ 12,216$, with hospitalization being the major cost driver $(81 \%)$, followed by barrier precautions (13\%), antimicrobial therapy $(4 \%)$ and laboratory investigations (2\%). The most recent epidemiological data, combined with available cost data, suggest that direct health care cost attributable to MRSA in Canada, including cost for management of MRSA-infected and-colonized patients and MRSA infrastructure, averaged $\$ 82$ million in 2004 and could reach $\$ 129$ million in 2010.

CONCLUSION: MRSA is a costly public health issue that needs to be tackled if the growing burden of this disease in Canadian hospitals and in the community is to be limited.

Key Words: Costs; Methicillin-resistant Staphylococcus aureus; Review

Staphylococcus aureus, on the skin or in the nasopharynx of Shumans, has colonized $30 \%$ to $50 \%$ of the population (1). The global SENTRY Antimicrobial Surveillance Program, a network of approximately 100 sentinel hospitals in Canada, the United States (US), Latin America, Europe and the West Pacific, demonstrated that $S$ aureus was the most prevalent cause of nosocomial and community-acquired bloodstream infections, skin and soft tissue infections (SSTIs) and pneumonia in almost all geographic areas (2). Although conflicting and inconsistent results have been reported, recent data suggest that patients with methicillin-resistant $S$ aureus (MRSA) infections have worse clinical and economic outcomes than patients with methicillin-susceptible $S$ aureus (MSSA) infections (3-5).

MRSA is endemic worldwide in hospitals, and communityassociated MRSA (CA-MRSA) is spreading into the community at large (6). Rates of MRSA ranging from 5.7\% in Canada

\section{Le staphylocoque doré méthicillinorésistant : Un problème de santé publique ayant des con- séquences économiques}

HISTORIQUE : Le staphylocoque doré méthicillinorésistant (SARM) est devenu endémique dans les hôpitaux du monde entier, tandis que le SARM non nosocomial se répand dans l'ensemble de la population. OBJECTIFS : Évaluer le coût actuel du SARM au Canada et l'importance de ce problème de santé publique.

MÉTHODOLOGIE : On a mené une analyse approfondie des publications scientifiques pour colliger des données d'épidémiologie, d'utilisation et de coût des ressources de santé pour le SARM dans le contexte canadien. On a estimé le fardeau actuel du SARM au moyen des données relatives aux coûts et des données épidémiologiques les plus récentes.

RÉSULTATS : Le taux de SARM dans les hôpitaux canadiens est passé de 0,46 à 5,90 cas sur 1000 hospitalisations entre 1995 et 2004, tandis que le SARM non nosocomial a continué de se propager dans la collectivité. Les patients atteints du SARM ont dû subir une hospitalisation prolongée (moyenne de 26 jours d'isolement par patient), des mesures de contrôle spéciales, des traitements coûteux et une surveillance étroite. Le coût total par patient infecté par le SARM était d'une moyenne de 12216 \$, l'hospitalisation étant le principal inducteur de coût (81\%), suivi des précautions antibiorésistantes (13\%), de la thérapie antimicrobienne (4\%) et des enquêtes de laboratoire (2\%). D’après les données épidémiologiques les plus récentes, combinées aux inducteurs de coût disponibles, les coûts de santé directs attribuables au SARM au Canada, y compris le coût de prise en charge des patients infectés et colonisés par le SARM et de l'infrastructure du SARM, atteignaient une moyenne de 82 millions de dollars en 2004 et pourraient atteindre 129 millions de dollars en 2010. CONCLUSION : Le SARM st un problème de santé publique coûteux auquel il faut s'attaquer pour limiter le fardeau croissant de cette maladie dans les hôpitaux canadiens et dans la collectivité.

to $34.2 \%$ in the US to $45.3 \%$ in Chile were reported in 2001 (2). Since 1995, the Canadian Nosocomial Infection Surveillance Program (CNISP), a collaboration involving sentinel hospitals across the country, has released surveillance data showing a 10-fold increase in the incidence of MRSA in Canadian hospitals between 1995 and 2003 (7-9).

CA-MRSA is an emerging cause of morbidity and mortality among healthy people (10-12). A meta-analysis of 10 surveys, including more than 8000 patients on three continents, reported a CA-MRSA colonization rate of 1.3\% (95\% CI 1.04 to 1.53 ), with significant heterogeneity among study populations (13). In Canada, although CA-MRSA was associated with only specific populations when it was first described (such as First Nations communities), it has since been associated with pediatric populations and the general population $(12-20)$

\footnotetext{
${ }^{1}$ BioMedCom Consultants Inc, Montreal, Quebec; ${ }^{2}$ Wyeth Pharmaceuticals, Markham, Ontario

Correspondence: Dr Mireille Goetghebeur, BioMedCom Consultants Inc, 6700, Côte-de-Liesse, Suite 105, Montreal, Quebec H4T 2B5.

Telephone 514-745-0915, fax 514-745-0916, e-mail mireille_goetghebeur@biomedcom.org

Received for publication May 18, 2006. Accepted July 21, 2006
} 
TABLE 1

Characteristics of community-associated methicillin-resistant Staphylococcus aureus (CA-MRSA) versus health care-associated MRSA

\begin{tabular}{|c|c|c|}
\hline & MRSA & CA-MRSA \\
\hline Groups at risk, and risk factors & $\begin{array}{l}\text { Prolonged hospitalization, intensive care unit admission, } \\
\text { hemodialysis or peritoneal dialysis, intravascular catheter, } \\
\text { diabetes, residents in long-term care institutions }\end{array}$ & $\begin{array}{l}\text { Children, prisoners, military personnel, amateur or } \\
\text { professional competitive athletes, selected ethnic } \\
\text { populations (First Nations communities), intravenous } \\
\text { drug users, men who have sex with men }\end{array}$ \\
\hline Clinical syndromes & $\begin{array}{l}\text { Wide variety of infections: nosocomial pneumonia, wound } \\
\text { infections, prosthesis infections, surgical site infections, } \\
\text { catheter-associated bacteremias (urinary tract, bloodstream) }\end{array}$ & $\begin{array}{l}\text { Specific syndrome of skin manifestations (folliculitis, } \\
\text { abscesses), severe infections such as necrotizing } \\
\text { pneumonia, necrotizing fasciitis and sepsis }\end{array}$ \\
\hline Antimicrobial resistance & Multidrug resistance & Beta-lactam resistance alone \\
\hline $\begin{array}{l}\text { Presence of exotoxin (Panton-Valentine } \\
\text { leukocidin toxin) }\end{array}$ & Rare & Frequent \\
\hline $\begin{array}{l}\text { Type of chromosomal element carrying } \\
\text { the methicillin-resistant gene }(\mathrm{SCCmec})\end{array}$ & Types IV and V & Types I, II and III \\
\hline
\end{tabular}

Data from references 1,10 and 31

Although the Canadian rate of MRSA is much lower than that observed in many other countries, its continuing spread will contribute to an increasing financial burden on Canadian health care resources (9). MRSA can be present in sputum, wounds and the bloodstream of infected patients, but also on apparently healthy skin, requiring extensive and costly barrier precautions to limit transmission (21). Several Canadian studies have explored resource utilization and costs associated with the management of MRSA patients (22-27). In the early 2000s, the MRSA financial burden in Canada ranged from $\$ 40$ to $\$ 59$ million $(22,24)$. The objectives of the present study were to estimate the current burden and cost of MRSA in Canada, and to assess the magnitude of this public health issue.

\section{METHODS}

In an extensive review of the literature, MEDLINE and databases from the Centre for Reviews and Dissemination < www.york.ac.uk/ inst/crd/crddatabases.htm $>$ were searched for the following key words: methicillin-resistant $S$ aureus, community-acquired, epidemiology, outbreaks, CNISP, SENTRY, PROTEKT, treatment patterns, clinical guidelines, recommendations, cost, burden and Canada. Searching by prominent authors in the field was also carried out. Selected journals, including The Canadian Journal of Infectious Diseases $\mathcal{E}^{2}$ Medical Microbiology, The Journal of the American Medical Association and The New England Journal of Medicine, were also searched. In addition, retrieved bibliographies were screened. Web sites were also searched, including the Public Health Agency of Canada <www.phac-aspc.gc.ca>, Health Canada <www.hc-sc.gc.ca>, the Canadian Committee on Antibiotic Resistance <www.ccar-ccra.com> and the Canadian Institute for Health Information <www.cihi.ca>.

Numbers of MRSA colonization or infection cases in Canada were obtained by multiplying the MRSA rate per 1000 admissions from the CNISP (Dr Andrew Simor, personal communication) (9) by the corresponding annual number of hospitalizations $(28,29)$.

Canadian costs for MRSA were collected from the literature. The total direct cost per infected MRSA patient included hospitalization, antimicrobial treatment, laboratory investigations and barrier precautions. Lost revenue from hospital rooms used for isolation was not considered. A range for cost per infected MRSA patient was estimated using minimum and maximum costs for each component.

Costs to the Canadian health care system included hospital costs for MRSA patients (infected or colonized) and costs for
MRSA infrastructure. Hospital costs were obtained by multiplying the estimated cost per patient by the number of MRSA cases. Annual costs for MRSA colonization and infection were projected to 2010 using separate linear regression models based on historical calculated costs, with cost as the dependent variable and year as the independent variable. Hospital admission rates for the corresponding time period were projected using the same methodology.

Canadian dollar estimates retrieved in the literature were adjusted for inflation using the Consumer Price Index (30). Currency years were assumed to be the same as the year of publication. All analyses were performed using Microsoft Excel (Microsoft Corporation, USA).

\section{RESULTS}

Types of MRSA and epidemiology in Canada

CA-MRSA strains differ from other nosocomial strains in clinically relevant ways, including a propensity to cause SSTIs and necrotizing pneumonia (Table 1) $(1,10,31)$. Patients at risk for CA-MRSA are generally younger and in better health than patients at risk for MRSA (10). Unlike multidrug-resistance patterns that typify nosocomial strains, CA-MRSA often expresses resistance to beta-lactams alone $(1,10,31)$. CA-MRSA is characterized by the presence of the Panton-Valentine leukocidin toxin and by the chromosomal element carrying the methicillin-resistant gene (1).

Recent studies from the CNISP have reported MRSA infection rates, determined using standard definitions (32), and MRSA colonization rates, defined as the presence of MRSA without signs or symptoms of infection (9). The most recent data from the CNISP indicate a combined increased incidence of MRSA infections and colonization in Canadian hospitals of approximately 12-fold between 1995 and 2004, from 0.46 to 5.90 per 1000 admissions (Dr Andrew Simor, personal communication) (9). Most of this occurred in Ontario and Quebec. During the same time period, MRSA infection incidence alone increased from 0.25 to 1.73 per 1000 admissions. In 2004, MRSA infection accounted for $34 \%$ of all MRSA cases (colonization and infection). The mean age of MRSA patients was 66 years. MRSA strains were resistant to multiple classes of antibiotics, but susceptibility to vancomycin was maintained (9). According to 2004 CNISP data, 72\% of MRSA cases likely were acquired in hospital, 3\% in long-term care facilities, $14 \%$ in the community and $10 \%$ from an undetermined origin. For 
community-originated MRSA, this represents a 1.75 -fold increase over 2003 data (9). Recently, in the Canadian National Intensive Care Unit (CAN-ICU) study, which involved 20 sites across the country, MRSA accounted for $21.2 \%$ of $S$ aureus isolates in Canadian intensive care units (ICUs) (33). The SENTRY Antimicrobial Surveillance Program, initiated in 1997 as a global network for longitudinal tracking of antimicrobial resistance, reported an overall MRSA rate in Canada of $5.7 \%$ from bloodstream isolates of nosocomial and community-onset origins (2).

In Canada, CA-MRSA was reported to be endemic in First Nations and Métis communities in northern Saskatchewan (34). Between 1990 and 1992, First Nations patients accounted for $62 \%$ of those MRSA-positive on hospital admission (35). Crowding, lack of good quality running water and heavy antibiotic use may have accounted for this (34). Several reports have also highlighted CA-MRSA spread in pediatric and general populations (12-20). The emergence of two different strains of MRSA was recently reported in Saskatchewan (19). In Manitoba, $40 \%$ of MRSA isolates collected by the provincial health laboratory were community acquired (18). CA-MRSA outbreaks were recently reported in a Canadian correctional facility in southern Ontario (20). In British Columbia, CA-MRSA is on the rise, with the proportion of isolates of community origin ranging from $25 \%$ to $70 \%$ (15). The first outbreak of severe CA-MRSA USA 300 infections was reported recently in Alberta in marginalized populations $(16,36)$. One study, which included 50 nursing homes in the US and Canada, reported that $33 \%$ of $S$ aureus isolates were MRSA (14). CA-MRSA was present in $10.9 \%$ of patients with communityacquired respiratory tract infections in Canada, versus 28.5\% in the US (17).

Although MRSA rates in Canada are still lower than in the US and elsewhere, its continued spread is concerning and is impressing a growing burden on Canadian health care resources, in hospitals and in the community.

\section{The management of MRSA and its associated costs}

A meta-analysis indicated that, compared with MSSA patients, MRSA patients are at increased risk for mortality $(\mathrm{OR}=1.93)$ (3). Differences in morbidity do not appear to be related to virulence, similar in both strains, but perhaps to the lesser efficacy of vancomycin used for MRSA than that of beta-lactams used for MSSA, and to the longer time until appropriate therapy is found for MRSA patients (4). MRSA strains are resistant to multiple antimicrobial agents, and treatment options are limited (37). Current guidelines in Canada recommend vancomycin as the treatment of choice for serious or invasive MRSA infection (37). Alternative treatments such as clindamycin, trimethoprim-sulfamethoxazole, minocycline, quinupristindalfopristin or linezolid are considered for susceptible organisms (37). The first MRSA strain with reduced susceptibility to vancomycin was recently reported in Alberta (38), emphasizing a pressing need for appropriate use of vancomycin and new options in the management of MRSA patients.

Canadian guidelines for CA-MRSA are underway, and a consensus conference was held on October 2006. US guidelines and a recent Canadian practitioner guide for the management of CA-MRSA SSTIs recommended oral antimicrobial therapy for patients with moderate infections $(10,39,40)$; for more severe cases, hospitalization and parenteral antimicrobials were preferred. Patients with CA-MRSA pneumonia should be treated in consultation with infectious disease and critical care specialists (10).

Treatment patterns in Canada were explored in a retrospective analysis of MRSA patients with SSTIs treated in teaching hospitals from three distinct geographical areas (41). Considerable variation in treatment patterns was observed, with a mean $( \pm$ SD) duration of anti-infective treatment of $22.4 \pm 21$ days and mean duration of hospitalization of 28.9 \pm 20.8 days (Table 2). Controlling MRSA infection can be expensive and labour intensive, and can cause considerable disruption of clinical services (42). Several Canadian studies have investigated health care resource utilization and the direct medical costs associated with MRSA infection (22,24-27). Substantial variation was observed among studies in methodologies used and depth of analyses, as well as in their measures of health care utilization, resources included in estimates, cost per component and total cost per patient (Table 2). Patients harbouring MRSA required prolonged hospitalization, varying from 14 to 36 days per patient in isolation (average 26 days). Cost per day of hospitalization also varied from $\$ 84$ to $\$ 917$, depending on the perspective considered. For example, Papia et al (25) considered only the portion paid by the hospital deducted from the reimbursable portion from patients with private insurance. Total hospitalization cost per patient ranged from $\$ 3,024$ to $\$ 12,835$.

The cost of antimicrobial therapy was included in only two studies, and varied between \$325 and \$574 (Table 2). Components of barrier precautions were detailed in two studies, while global costs were reported in three, ranging from $\$ 806$ to $\$ 2,086$ per patient. Nursing time, as well as the cost of gowns, gloves and masks, were the major components of cost for barrier precautions. Cost estimates for laboratory investigations varied considerably, with a minimum of $\$ 125$ and a maximum of $\$ 315$.

Based on available data, low and high estimates of cost per hospitalized patient infected with MRSA were calculated, including hospitalization, barrier precautions, antimicrobial therapy and laboratory investigations. For hospitalization cost, the full daily cost of $\$ 210$ reported by Papia et al (25) was used, including any portion reimbursable by private insurance. For total costs, using the minimum cost for each component, the low estimate amounted to $\$ 6,878$ per patient; the high estimate was $\$ 17,553$ per patient. Minimum and maximum costs for each component were averaged, and the total average cost per infected MRSA patient amounted to $\$ 12,216$, with hospitalization the major cost driver ( $81 \%)$, followed by barrier precautions (13\%), antimicrobial therapy $(4 \%)$ and laboratory investigations (2\%) (Figure 1).

\section{Estimating the cost of MRSA to the Canadian health care system}

Low and high estimates for the total cost of MRSA to the Canadian health care system was calculated considering MRSA infection, MRSA colonization and MRSA infrastructure for surveillance (Table 3). Low and high estimates for cost per patient with MRSA infection (estimated above) were used. For MRSA colonization, only one estimate was available in the literature. Published estimates for MRSA infrastructure varied between $\$ 3,000$ and $\$ 7,000$. After adjusting with the Consumer Price Index, cost data combined with epidemiological data suggested that the direct health care cost attributable to MRSA in Canada ranges from $\$ 54$ million to $\$ 110$ million annually. 
TABLE 2

Health care utilization and associated costs for the management of methicillin-resistant Staphylococcus aureus (MRSA) patients in Canada

\begin{tabular}{|c|c|c|c|c|c|}
\hline Study & Health care resource & Unit & Quantity & Unit cost & Cost per patient \\
\hline Conly, 2003 (41) & Hospitalization & Days & 28.9 & Not applicable & Not applicable \\
\hline - Tertiary care hospitals & Antimicrobial therapy & Days & 22.4 & Not applicable & Not applicable \\
\hline - British Columbia, Ontario and Quebec & Intravenous vancomycin & Days & 19.5 & Not applicable & Not applicable \\
\hline \multicolumn{6}{|l|}{ - Skin and soft tissue infections only } \\
\hline Kim et al, 2001 (22) & Hospitalization & Days & 14 & $\$ 916.83^{*}$ & $\$ 12,835.60^{*}$ \\
\hline - Tertiary care hospitals & Antimicrobial therapy & - & - & - & $\$ 574.40^{*}$ \\
\hline \multirow[t]{5}{*}{ - Ontario } & Laboratory investigations & Specimen & - & $\$ 8.34$ & $\$ 143.60^{*}$ \\
\hline & Barrier precautions & Contact & 60/day & $\$ 0.96$ & $\$ 806.40^{*}$ \\
\hline & MRSA surveillance & Specimen & - & $\$ 5.50$ & - \\
\hline & Total cost/MRSA infection & - & - & - & $\$ 14,360.00$ \\
\hline & Total cost/MRSA colonization & - & - & - & $\$ 1,363.00$ \\
\hline Canada Communicable Disease Report, & Hospitalization & Days & 28 & $\$ 185.00$ & $\$ 5,180.00$ \\
\hline $2002(24)$ & Laboratory investigations & Specimen & 21 & $\$ 15.00$ & $\$ 315.00$ \\
\hline - General hospitals & Total barrier precautions* & - & - & - & $\$ 1,727.00$ \\
\hline \multirow[t]{7}{*}{ - Ontario } & Added nursing time & Days & 1.12 & $\$ 576.00$ & $\$ 645.00$ \\
\hline & Gowns and masks & Each & $50 \times 28$ & $\$ 0.40$ & $\$ 560.00$ \\
\hline & Examination gloves & Each & 28 & $\$ 7.00$ & $\$ 196.00$ \\
\hline & Mupirocin ointment masks & Each & 3 & $\$ 15.00$ & $\$ 45.00$ \\
\hline & Chlorhexidine gluconate & Bottle & 4 & $\$ 2.35$ & $\$ 9.00$ \\
\hline & Environmental cleaning & Days & 15.25 & $\$ 17.82$ & $\$ 272.00$ \\
\hline & Total cost to hospital (antimicrobials not included) & - & - & - & $\$ 7,222.00$ \\
\hline \multirow[t]{8}{*}{ Papia et al, 1999 (25) } & Hospitalization ${ }^{\dagger}$ & Days & 36 & $\$ 210.00$ & $\$ 7,560.00$ \\
\hline & Laboratory investigations & Specimen & 15 & $\$ 8.34$ & $\$ 125.00$ \\
\hline & Total barrier precautions* & - & - & - & $\$ 2,086.00$ \\
\hline & Added nursing time & Min & $60 \times 36$ & $\$ 0.36$ & $\$ 778.00$ \\
\hline & Gowns and gloves & Each & $60 \times 36$ & $\$ 0.60$ & $\$ 1,296.00$ \\
\hline & $2 \%$ mupirocin & - & - & - & $\$ 7.40$ \\
\hline & $4 \%$ chlorhexidine gluconate & - & - & - & $\$ 5.04$ \\
\hline & Total cost to hospital (antimicrobials not included) & - & - & - & $\$ 9,771.00$ \\
\hline Rosner et al, 2004 (26) & Hospitalization & Days & 21.4-23.4 & $\$ 401.00$ & $\$ 6,191.00-\$ 6,979.00$ \\
\hline - Model based on data from tertiary & Antimicrobial therapy & Days & $21.1-20.8$ & - & $\$ 325.00-\$ 358.00$ \\
\hline care hospitals & Professional fees & - & - & - & $\$ 509.00-\$ 984.00$ \\
\hline - British Columbia, Ontario, Quebec & Outpatient intravenous antimicrobial & - & - & - & $\$ 74.00-\$ 370.00$ \\
\hline \multirow[t]{3}{*}{ - Skin and soft tissue infections only } & Outpatient oral antimicrobial & - & - & - & $\$ 0-\$ 378.00$ \\
\hline & Home intravenous care service & - & - & - & $\$ 12.00-\$ 227.00$ \\
\hline & Total cost to Ministry of Health and Long-term Care & - & - & - & $\$ 7,693.00-\$ 8,444.00$ \\
\hline Bryce et al, 2000 (27) & Hospitalization & - & - & - & $\$ 6,500.00$ \\
\hline - Tertiary care hospital & Laboratory investigations and barrier precautions & - & - & - & $\$ 4,345.00$ \\
\hline - British Columbia & Total cost to hospital (antimicrobial not included) & - & - & - & $\$ 10,845.00$ \\
\hline Gardam et al, 2001 (23) & Total cost - protocol MSA-4 & Specimen & - & - & $\$ 3.83$ \\
\hline - University-affiliated laboratory & Laboratory cost & Specimen & - & - & $\$ 1.33$ \\
\hline \multirow[t]{4}{*}{ - Ontario } & Laboratory technologist cost & Specimen & - & - & $\$ 2.50$ \\
\hline & Total cost - protocol M-SAM & Specimen & - & - & $\$ 8.05-\$ 9.30$ \\
\hline & Laboratory cost & Specimen & - & - & $\$ 4.31$ \\
\hline & Laboratory technologist cost & Specimen & - & - & $\$ 3.74-\$ 4.99$ \\
\hline
\end{tabular}

*Numbers calculated from data available in published document; †Daily cost per room was $\$ 210$; costs included in the estimate by Papia et al were only those incurred by the hospital (\$84), assuming that $60 \%$ were recovered from the patient. M-ASM Broth-containing protocol as recommended by the American Society for Microbiology; MSA-4 Mannitol-salt agar containing $4 \mu \mathrm{g} / \mathrm{mL}$ of oxacillin

Trends in the annual cost of MRSA infection and colonization were estimated for the past 10 years using the average cost per patient of $\$ 12,216$, derived from the literature (Figure 2). Between 1995 and 2004, annual costs of MRSA infection and colonization increased from $\$ 10.6$ million to $\$ 76.4$ million (in 2005 dollars) (Figure 2). This increasing economic burden was attributable to a continuous rise in the incidence of MRSA over 10 years, approximately 20-fold for colonization and sevenfold for infection. The cost increase was observed despite an $11.3 \%$ decrease in hospital admissions, from 3,140,659 in 1994 to 2,786,545 in 2004. Projected costs based on historical data suggest that the annual cost of MRSA 
TABLE 3

Annual cost estimate of methicillin-resistant Staphylococcus aureus (MRSA) to the Canadian health care system - 2004

\begin{tabular}{|c|c|c|c|c|c|c|c|c|}
\hline & $\begin{array}{c}\text { Rate/1000 } \\
\text { admissions* }\end{array}$ & $\begin{array}{c}\text { Number of } \\
\text { hospitalizations }^{\dagger}\end{array}$ & $\begin{array}{l}\text { Number } \\
\text { of cases }\end{array}$ & \multicolumn{2}{|c|}{$\begin{array}{l}\text { Cost per patient }^{\ddagger} \\
(2005 \text { dollars })\end{array}$} & \multicolumn{2}{|c|}{$\begin{array}{r}\text { Cost in Canada } \\
(2005 \text { dollars) } \\
\end{array}$} & Average \\
\hline MRSA infection & 1.73 & $2,786,545$ & 4821 & $\$ 6,878$ & $\$ 17,553$ & $\$ 33,157,558$ & $\$ 84,619,546$ & $\$ 58,888,552$ \\
\hline MRSA infrastructure $§$ & & & & & & $\$ 3,191,860$ & $\$ 7,736,842$ & $\$ 5,464,351$ \\
\hline Total cost & & & & & & $\$ 53,848,977$ & $\$ 109,855,947$ & $\$ 81,852,462$ \\
\hline
\end{tabular}

*Unpublished data; ${ }^{\dagger}$ Data from reference 29; ${ }^{\star}$ Estimated from minimum and maximum for each cost component published in the literature (see Table 2) and adjusted for inflation with the Consumer Price Index ; §Data from references 22 and 24

infection and colonization may reach \$123.6 million in 2010 (Figure 2). Assuming a constant cost for MRSA infrastructure, the total MRSA cost will amount to \$129 million in 2010.

\section{DISCUSSION}

The rate of MRSA in Canadian hospitals increased more than 10-fold between 1995 and 2004, while CA-MRSA continued to spread in the community. Patients harbouring MRSA required prolonged hospitalization (26 days on average), special control measures, expensive treatments and extensive surveillance, resulting in an average total cost per MRSA-infected patient of $\$ 12,216$. The direct health care cost attributable to MRSA in Canada, including management of MRSA-infected and -colonized patients and MRSA infrastructure, averaged $\$ 82$ million in 2004 and may reach \$129 million in 2010.

Although MRSA rates in Canada have increased sharply over the past 10 years, they remain below that observed in the US and other countries. In 2003 in the US, MRSA accounted for 59.5\% of $S$ aureus isolates in ICUs, $46 \%$ in non-ICU inpatient areas and $31.1 \%$ in outpatient areas (43). Important differences in MRSA rates observed across countries are likely related to variations in antimicrobial use and infection control practices (2). There is some controversy regarding the feasibility and usefulness of barrier precautions in hospitals (44). Programs that have been effective at reducing transmission of MRSA have included active surveillance cultures of high-risk patients, contact precautions, hand hygiene and treatment of health care workers implicated in transmission (21). Although decolonization of colonized MRSA patients has been used to reduce the reservoir of MRSA during outbreaks, current Canadian guidelines for the management of MRSA do not support the routine use of antimicrobial therapy for eradicating MRSA colonization in hospitalized patients (37). This is not advisable because eradication cannot be guaranteed and there is a risk of developing resistance to decolonization agents (44). Measures to limit the spread of MRSA in the community include antimicrobial stewardship, personal and caregiver hygiene measures, environmental and organizational control measures, and health care-initiated measures $(10,15,39)$.

The present review indicated that Canadian patients infected with MRSA required prolonged hospitalization (average 26 days, range 14 to 36 days), comprising, on average, $81 \%$ of the total cost. Several studies have indicated that appropriate switching of MRSA patients from intravenous to oral treatment could reduce the length of hospital stay and cost per infected patient $(26,41,45)$, suggesting that oral therapy may be one strategy to reduce the economic impact of MRSA. Cost estimates in the literature have varied from $\$ 7,222$ to $\$ 14,630$ per infected MRSA patient in Canada. Such variations across studies may be

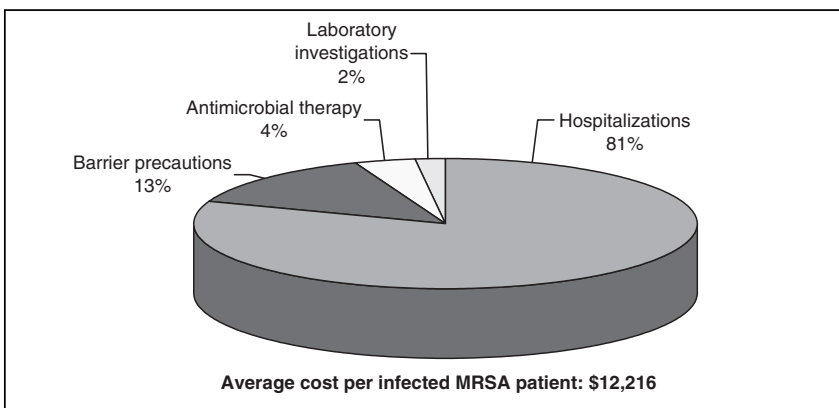

Figure 1) Breakdown of costs for the management of a patient hospitalized with a methicillin-resistant Staphylococcus aureus (MRSA) infection

attributable to differences in disease management, health care utilization, costing methodology and complexity of cases.

The average cost of $\$ 12,216$ per hospitalized MRSA patient presented in this study is in the lower range of those reported in other countries $(4,5)$. Several US studies have reported total costs between US $\$ 16,575$ and $\$$ US39,400 per MRSA patient (4,5,46-48). A French study reported a mean cost per MRSA infected patient of US $\$ 9,275$ (49). Another US study reporting cost by type of infection found total costs per MRSA patient of US $\$ 23,616$ for SSTIs, US $\$ 26,446$ for bacteremia, US $\$ 48,925$ for infective endocarditis and US $\$ 48,945$ for hospital-acquired pneumonia (50). Some studies also compared the cost of MRSA infection with that of MSSA infection and reported a 1.4- to 2.8-fold increase in cost per patient, highlighting the increased burden associated with resistance $(4,5,46,47)$.

In the present study, the total cost to the Canadian health care system ranged from $\$ 54$ million to $\$ 110$ million annually, with MRSA infection only ranging from $\$ 33.2$ to $\$ 84.6$ million (4821 cases, with a cost per patient of $\$ 6,878$ to $\$ 17,553$ ). Previous estimates in Canada reported a range from $\$ 40$ million to $\$ 59$ million $(22,24)$. One recent US study estimated the annual cost of treating patients hospitalized with MRSA infections to be between US $\$ 3.2$ billion and US $\$ 4.7$ billion $(120,000$ cases, with a cost per patient of US $\$ 27,083$ to US $\$ 34,900$ ) (48). Although MRSA rates and overall costs are still much lower in Canada than in the US, continuously increasing rates have resulted in a significant increase of burden to Canadians. Projected costs based on historical data suggest that the average total cost of MRSA, estimated at $\$ 82$ million in 2004, may reach $\$ 129$ million in 2010.

Cost estimates in the present paper underestimate the global cost of MRSA, because they do not include the costs of 


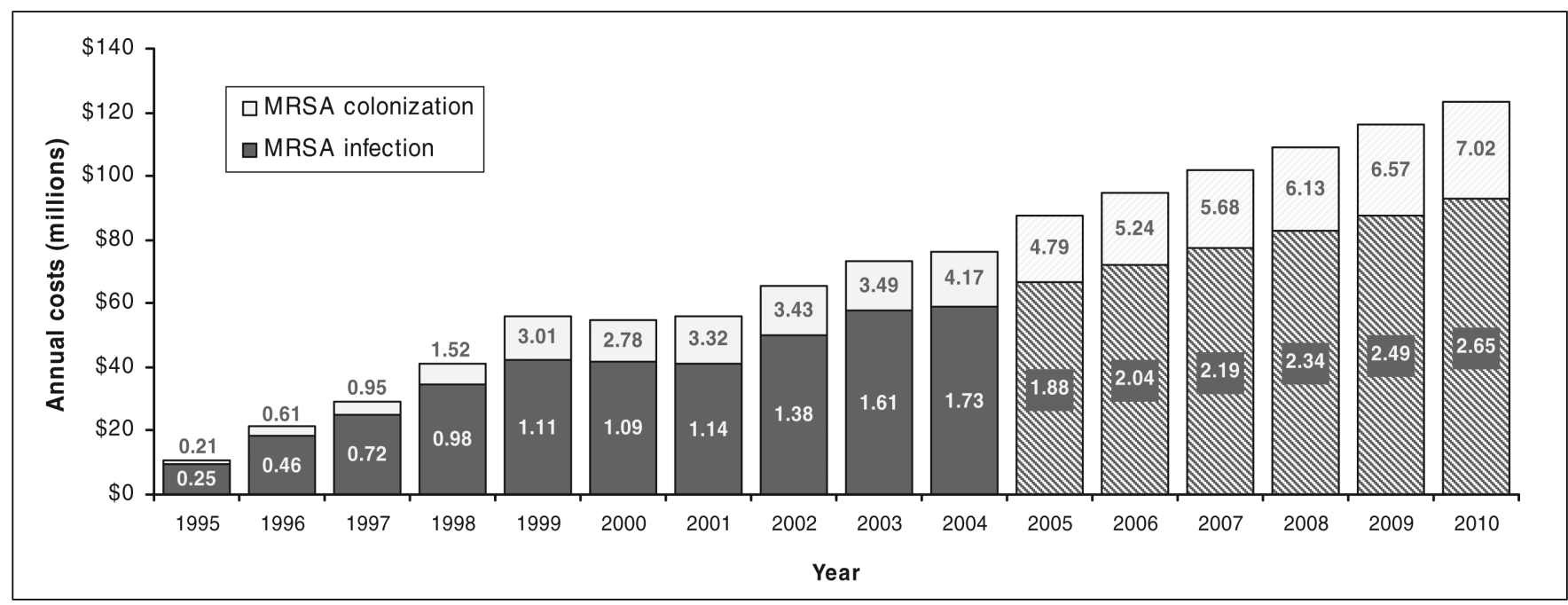

Figure 2) Estimated annual cost of methicillin-resistant Staphylococcus aureus (MRSA) infection and colonization in Canada - 1995 to 2010. Numbers in graph indicate incidence of MRSA (rate per 1000 admissions); hatched bars indicate projected annual costs based on historical data. Costs based on the Canadian dollar in 2005

CA-MRSA, the costs of outbreak management (in addition to the cost of managing infection, such as cost of service disruption, etc) or indirect costs. There are limited countrywide data on CA-MRSA incidence or on the cost of CA-MRSA in Canada. However, the rising number of CA-MRSA infections associated with severe soft tissue infections and necrotizing pneumonia $(16,51,52)$ is likely to have a significant human and financial impact. There were insufficient published data to quantify cost of outbreaks in terms of disruption of clinical activity. In the Netherlands, the cost to bring an outbreak of MRSA under control was approximately US $\$ 250,000$, including closing ICUs, postponing operations, laboratory investigations and other unspecified measures; no breakdown was available to estimate the contribution of each component (53). Several other studies have reported outbreak cost, but they either represented costs already covered in our analysis or did not sufficiently detail the contribution of other cost components. An outbreak in Australia was estimated to cost AUS $\$ 90,000$ (54); outbreak cost varied from US $\$ 13,000$ to US $\$ 144,000(55,56)$ in the US, and from $£ 13,000$ to $£ 80,000$ in the United Kingdom $(57,58)$.

Limited data exist on indirect costs of MRSA. One Canadian study reported that patients who have suffered drug-resistant infections endure physical, emotional, financial and psychological harm, but no dollar value was assigned to these human costs (24). Given the required isolation, the long-term nature of some infections and the need for outpatient treatment for wound care or intravenous treatment (24), the toll on quality of life and productivity is likely to be significant, especially for CA-MRSA affecting younger people in good general health.

The limitations of those cost estimates should be considered. Although we attempted to account for variations between studies by averaging extreme values, most data were from tertiary care hospitals and not necessarily representative of Canadian hospitals. Only one source of incidence data was used (CNISP), and it has been suggested that it may underestimate MRSA rates (22). The cost of intravenous therapy was underestimated, because most of the studies that were reviewed considered only acquisition cost of antimicrobials, not administration. A US study reported that when costs for material, preparation, administration, monitoring, adverse events and therapeutic failure were included, the cost of using vancomycin was three to five times that of its acquisition (50). Cost of treatment failure was not assessed, although current treatment options for MRSA patients are of limited efficacy (59). In this respect, new generations of broad-spectrum antimicrobials, such as tigecycline, the first-in-class glycylcycline that overcomes major resistance mechanisms (ribosomal protection and active drug efflux), and the cephalosporin ceftobiprole, promise more efficacious management of MRSA patients (59-62).

\section{CONCLUSIONS}

The present study describes MRSA as a costly public health issue that needs to be tackled if the growing burden of this disease is to be limited. No simple solution exists to prevent escalation to those rates observed in the US and elsewhere. Coordinated leadership, compliance with barrier precautions, use of efficacious, first-line antimicrobials and guidelines for proper use of new antimicrobials are some available avenues. The feasibility of community control of CA-MRSA is debatable, highlighting the pressing need for effective agents against MRSA and rational use of antibiotics to limit resistance.

ACKNOWLEDGEMENTS: The authors wish to thank Andrew E Simor MD, Sunnybrook and Women's College Health Sciences Centre, Toronto, Ontario, for his valuable input to this manuscript, and Donna Rindress PhD, BioMedCom Consultants Inc, for her critical review. This study was made possible by a grant from Wyeth Pharmaceuticals.

CONFLICTS OF INTEREST: Colin Vicente and Donald Han are employed by Wyeth Pharmaceuticals. Mireille Goetghebeur and Pierre-Alexandre Landry are employed by BioMedCom Consultants Inc and received financial compensation for consultancy services.

\section{REFERENCES}

1. Furuya EY, Lowy FD. Antimicrobial-resistant bacteria in the community setting. Nat Rev Microbiol 2006;4:36-45.

2. Diekema DJ, Pfaller MA, Schmitz FJ, et al. Survey of infections due to Staphylococcus species: Frequency of occurrence and antimicrobial susceptibility of isolates collected in the United States, Canada, Latin America, Europe, and the Western Pacific region for the 
SENTRY Antimicrobial Surveillance Program, 1997-1999.

Clin Infect Dis 2001;32:S114-32.

3. Cosgrove SE, Sakoulas G, Perencevich EN, Schwaber MJ, Karchmer AW, Carmeli Y. Comparison of mortality associated with methicillin-resistant and methicillin-susceptible Staphylococcus aureus bacteremia: A meta-analysis. Clin Infect Dis 2003;36:53-9.

4. Lodise TP, McKinnon PS. Clinical and economic impact of methicillin resistance in patients with Staphylococcus aureus bacteremia. Diagn Microbiol Infect Dis 2005;52:113-22.

5. Kopp BJ, Nix DE, Armstrong EP. Clinical and economic analysis of methicillin-susceptible and -resistant Staphylococcus aureus infections. Ann Pharmacother 2004;38:1377-82.

6. World Health Organization. Overcoming antimicrobial resistance. World Health Report on Infectious Diseases 2000.

$<$ http://www.who.int/infectious-disease-report/2000/other_versions/ index-rpt2000_text.html> (Version current at February 5, 2007).

7. Simor A, Ofner-Agostini M, Paton S. The Canadian Nosocomial Infection Surveillance Program: Results of the first 18 months of surveillance for methicillin-resistant Staphylococcus aureus in Canadian hospitals. Can Commun Dis Rep 1997;23:41-5.

8. Simor AE, Ofner-Agostini M, Bryce E, et al. The evolution of methicillin-resistant Staphylococcus aureus in Canadian hospitals: 5 years of national surveillance. CMAJ 2001;165:21-6.

9. Simor AE, Ofner-Agostini M, Gravel D, et al. Surveillance for methicillin-resistant Staphylococcus aureus in Canadian hospitals A report update from the Canadian Nosocomial Infection Surveillance Program. Can Commun Dis Rep 2005;31:33-40.

10. Kowalski TJ, Berbari EF, Osmon DR. Epidemiology, treatment, and prevention of community-acquired methicillin-resistant Staphylococcus aureus infections. Mayo Clin Proc 2005;80:1201-7.

11. Conly J, Johnston BL. The emergence of methicillin-resistant Staphylococcus aureus as a community-acquired pathogen in Canada. Can J Infect Dis Med Microbiol 2003;14:249-51.

12. Centers for Disease Control and Prevention. From the Centers for Disease Control and Prevention. Four pediatric deaths from community-acquired methicillin-resistant Staphylococcus aureus Minnesota and North Dakota, 1997-1999. JAMA 1999;282:1123-5.

13. Salgado CD, Farr BM, Calfee DP. Community-acquired methicillinresistant Staphylococcus aureus: A meta-analysis of prevalence and risk factors. Clin Infect Dis 2003;36:131-9.

14. Loeb MB, Craven S, McGeer AJ, et al. Risk factors for resistance to antimicrobial agents among nursing home residents. Am J Epidemiol 2003;157:40-7.

15. BC Centre for Disease Control. A report on the emergence of community-acquired methicillin-resistant Staphylococcus aureus (CA-MRSA) in British Columbia. <http://www.bccdc.org/ download.php?item $=2175>($ Version current at September 13, 2006).

16. Gilbert M, MacDonald J, Gregson D, et al. Outbreak in Alberta of community-acquired ( $\mathrm{USA}_{300}$ ) methicillin-resistant Staphylococcus aureus in people with a history of drug use, homelessness or incarceration. Can Med Assoc J 2006;175:149-54.

17. Hoban D, Waites K, Felmingham D. Antimicrobial susceptibility of community-acquired respiratory tract pathogens in North America in 1999-2000: Findings of the PROTEKT surveillance study. Diagn Microbiol Infect Dis 2003;45:251-9.

18. Wylie JL, Nowicki DL. Molecular epidemiology of community- and health care-associated methicillin-resistant Staphylococcus aureus in Manitoba, Canada. J Clin Microbiol 2005;43:2830-6.

19. Mulvey MR, MacDougall L, Cholin B, Horsman G, Fidyk M, Woods S. Community-associated methicillin-resistant Staphylococcus aureus, Canada. Emerg Infect Dis 2005;11:844-50.

20. Main CL, Jayaratne P, Haley A, Rutherford C, Smaill F, Fisman DN. Outbreaks of infection caused by community-acquired methicillin-resistant Staphylococcus aureus in a Canadian correctional facility. Can J Infect Dis Med Microbiol 2005;16:343-8.

21. Boyce JM, Havill NL, Kohan C, Dumigan DG, Ligi CE. Do infection control measures work for methicillin-resistant Staphylococcus aureus? Infect Control Hosp Epidemiol 2004;25:395-401.

22. Kim T, Oh PI, Simor AE. The economic impact of methicillinresistant Staphylococcus aureus in Canadian hospitals. Infect Control Hosp Epidemiol 2001;22:99-104.
23. Gardam M, Brunton J, Willey B, McGeer A, Low D, Conly J. A blinded comparison of three laboratory protocols for the identification of patients colonized with methicillin-resistant Staphylococcus aureus. Infect Control Hosp Epidemiol 2001;22:152-6.

24. Public Health Agency of Canada. Canada Communicable Disease Report. Antimicrobial resistance: A deadly burden no country can afford to ignore. $<$ http://www.phac-aspc.gc.ca/publicat/ccdr-rmtc/ 03vol29/dr2918eb.html> (Version current at February 5, 2007).

25. Papia G, Louie M, Tralla A, Johnson C, Collins V, Simor AE. Screening high-risk patients for methicillin-resistant Staphylococcus aureus on admission to the hospital: Is it cost effective? Infect Control Hosp Epidemiol 1999;20:473-7.

26. Rosner AJ, Becker DL, Wong AH, Miller E, Conly J. The costs and consequences of methicillin-resistant Staphylococcus aureus infection treatments in Canada. Can J Infect Dis Med Microbiol 2004;15:213-20.

27. Bryce EA, Tiffin SM, Isaac-Renton JL, Wright CJ. The cost of doing business: Managing MRSA and VRE. Infect Control Hosp Epidemiol 2000;21:119.

28. Canadian Institute for Health Information. Hospital trends in Canada. $<$ http://secure.cihi.ca/cihiweb/dispPage.jsp?cw_page=AR_1215_E $>$ (Version current at February 5, 2007).

29. Canadian Institute for Health Information. Inpatient hospitalizations and average length of stay trends in Canada, 2003-2004 and 2004-2005. <http://secure.cihi.ca/cihiweb/en/downloads/ HMDB_Analysis_in_Brief_FINAL_ENG.pdf $>$ (Version current at February 5, 2007)

30. Bank of Canada. Rates and statistics: Inflation calculator. $<$ http://www.bankofcanada.ca/en/rates/inflation_calc.html> (Version current at February 5, 2007).

31. Boyce JM, Cookson B, Christiansen K, et al. Methicillin-resistant Staphylococcus aureus. Lancet Infect Dis 2005;5:653-63.

32. Garner JS, Jarvis WR, Emori TG, Horan TC, Hughes JM. CDC definitions for nosocomial infections, 1988. Am J Infect Control 1988;16:128-40.

33. De Corby M, Laing N, Weshnoweski B, et al. Antimicrobial resistance in pathogens isolated from Canadian intensive care units: Results of the Canadian National Intensive Care Unit (CAN-ICU) Study 2005. Association of Medical Microbiology and Infectious Disease (AMMI) Annual Meeting. Victoria,March 15 to 19, 2006

34. Canadian Paediatric Society. Methicillin-resistant Staphylococcus aureus in First Nations communities in Canada. Paediatr Child Health 2005;10:557-9.

35. Embil J, Ramotar K, Romance L, et al. Methicillin-resistant Staphylococcus aureus in tertiary care institutions on the Canadian prairies 1990-1992. Infect Control Hosp Epidemiol 1994;15:646-51.

36. Allen UD. Public health implications of MRSA in Canada. Can Med Assoc J 2006;175:161-2.

37. Simor AE, Loeb M. The management of infection and colonization due to methicillin-resistant Staphylococcus aureus: A CIDS/CAMM position paper. Can J Infect Dis Med Microbiol 2004;15:39-48.

38. Webster D, Rennie R, Brosnikoff C, Chui L, Brown C. Methicillinresistant Staphylococcus aureus with reduced susceptibility to vancomycin. Can J Infect Dis Med Microbiol 2005;16:140.

39. Nicolle L. Community-acquired MRSA: A practitioner's guide. Can Med Assoc J 2006;175:145-6.

40. Dellit T, Duchin J, Hofmann J, Gurmai Olson E. Interim guidelines for evaluation and management of community-associated methicillin resistant Staphylococcus aureus skin and soft tissue infections in outpatient settings. < http://www.metrokc.gov/health/prevcont/ mrsa.htm $>$ (Version current at February 5, 2007).

41. Conly J. A retrospective analysis of practice patterns in the treatment of methicillin-resistant Staphylococcus aureus skin and soft tissue infections at three Canadian tertiary care centres. Can J Infect Dis Med Microbiol 2003;14:315-21.

42. Boyce JM. Should we vigorously try to contain and control methicillin-resistant Staphylococcus aureus? Infect Control Hosp Epidemiol 1991;12:46-54.

43. National Nosocomial Infections Surveillance. National Nosocomial Infections Surveillance (NNIS) System Report, data summary from January 1992 through June 2004, issued October 2004. Am J Infect Control 2004;32:470-85.

44. Rotstein C. Hospital-acquired methicillin-resistant Staphylococus aureus: Epidemiology, treatment and control. Can J Infect Dis Med Microbiol 2006;17(Suppl B):13B-8B. 
45. Parodi S, Rhew DC, Goetz MB. Early switch and early discharge opportunities in intravenous vancomycin treatment of suspected methicillin-resistant staphylococcal species infections. J Manag Care Pharm 2003;9:317-26.

46. Cosgrove SE, Qi Y, Kaye KS, Harbarth S, Karchmer AW, Carmeli Y. The impact of methicillin resistance in Staphylococcus aureus bacteremia on patient outcomes: Mortality, length of stay, and hospital charges. Infect Control Hosp Epidemiol 2005;26:166-74.

47. Abramson MA, Sexton DJ. Nosocomial methicillin-resistant and methicillin-susceptible Staphylococcus aureus primary bacteremia: At what costs? Infect Control Hosp Epidemiol 1999;20:408-11.

48. Rojas EG, Liu LZ. Annual cost for the treatment of patients hospitalized with methicillin-resistant Staphylococcus aureus in the United States. Value Health 2005;8:308. (Abst)

49. Chaix C, Durand-Zaleski I, Alberti C, Brun-Buisson C. Control of endemic methicillin-resistant Staphylococcus aureus: A cost-benefit analysis in an intensive care unit. JAMA 1999;282:1745-51.

50. Shah NP, Reddy P, Paladino JA, McKinnon PS, Klepser ME, Pashos CL. Direct medical costs associated with using vancomycin in methicillin-resistant Staphylococcus aureus infections: An economic model. Curr Med Res Opin 2004;20:779-90.

51. Conly J, Gilbert M, Zhang K, et al. Rapidly progressive fatal necrotizing pneumonitis FNP 20 to panton-valentine leukocidin PVL + SCCmec type IVa community-acquired methicillin-resistant $S$ aureus CAMRSA - A harbinger of the future? Can J Infect Dis Med Microbiol 2005;16:109. (Abst)

52. Acker A, Onyett H. Case report of invasive community-acquired MRSA infection in an adolescent girl. Can J Infect Dis Med Microbiol 2005;16:128. (Abst)
53. Verhoef J, Beaujean D, Blok H, et al. A Dutch approach to methicillin-resistant Staphylococcus aureus. Eur J Clin Microbiol Infect Dis 1999;18:461-6.

54. Pavillard R, Harvey K, Douglas D, et al. Epidemic of hospital-acquired infection due to methicillin-resistant Staphylococcus aureus in major Victorian hospitals. Med J Aust 1982;1:451-4.

55. Walsh TJ, Vlahov D, Hansen SL, et al. Prospective microbiologic surveillance in control of nosocomial methicillin-resistant Staphylococcus aureus. Infect Control $1987 ; 8: 7-14$

56. Rao N, Jacobs S, Joyce L. Cost-effective eradication of an outbreak of methicillin-resistant Staphylococcus aureus in a community teaching hospital. Infect Control Hosp Epidemiol $1988 ; 9: 255-60$

57. Mehtar S, Drabu YJ, Mayet F. Expenses incurred during a 5-week epidemic methicillin-resistant Staphylococcus aureus outbreak. J Hosp Infect 1989;13:199-200.

58. Lacey RW. Multi-resistant Staphylococcus aureus - A suitable case for inactivity? J Hosp Infect 1987;9:103-5.

59. Schmidt-Ioanas M, de Roux A, Lode H. New antibiotics for the treatment of severe staphylococcal infection in the critically ill patient. Curr Opin Crit Care 2005;11:481-6.

60. Wenzel R, Bate G, Kirkpatrick P. Tigecycline. Nat Rev Drug Discov 2005;4:809-10.

61. Zhanel GG, Karlowsky JA, Rubinstein E, Hoban DJ. Tigecycline: A novel glycylcycline antibiotic. Expert Rev Anti Infect Ther 2006;4:9-25.

62. Chambers HF. Ceftobiprole: In-vivo profile of a bactericidal cephalosporin. Clin Microbiol Infect 2006;12:17-22. 


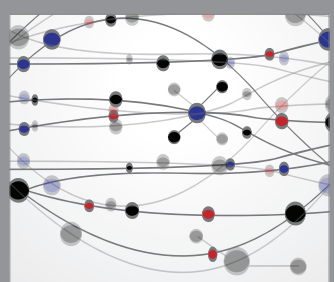

The Scientific World Journal
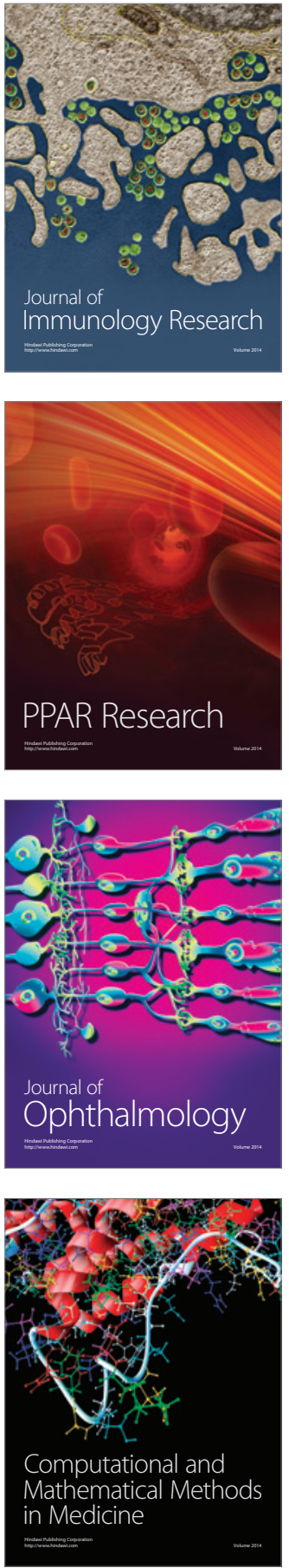

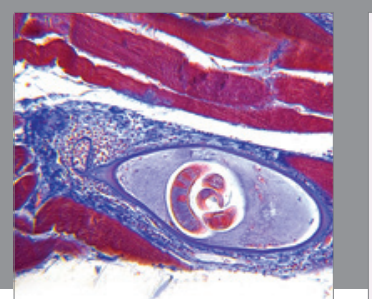

Gastroenterology Research and Practice

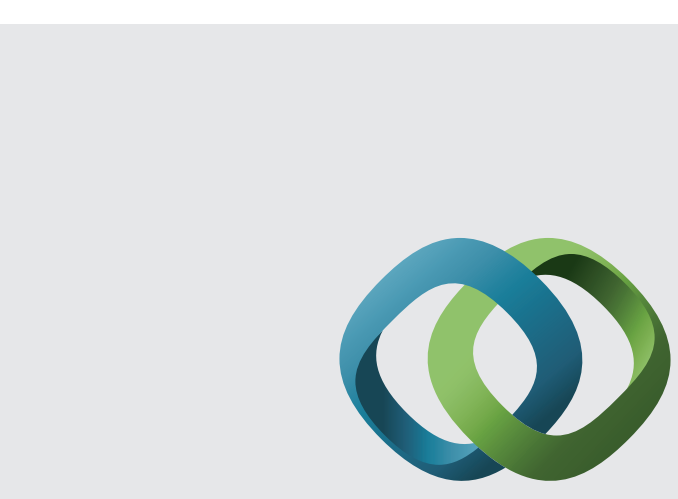

\section{Hindawi}

Submit your manuscripts at

http://www.hindawi.com
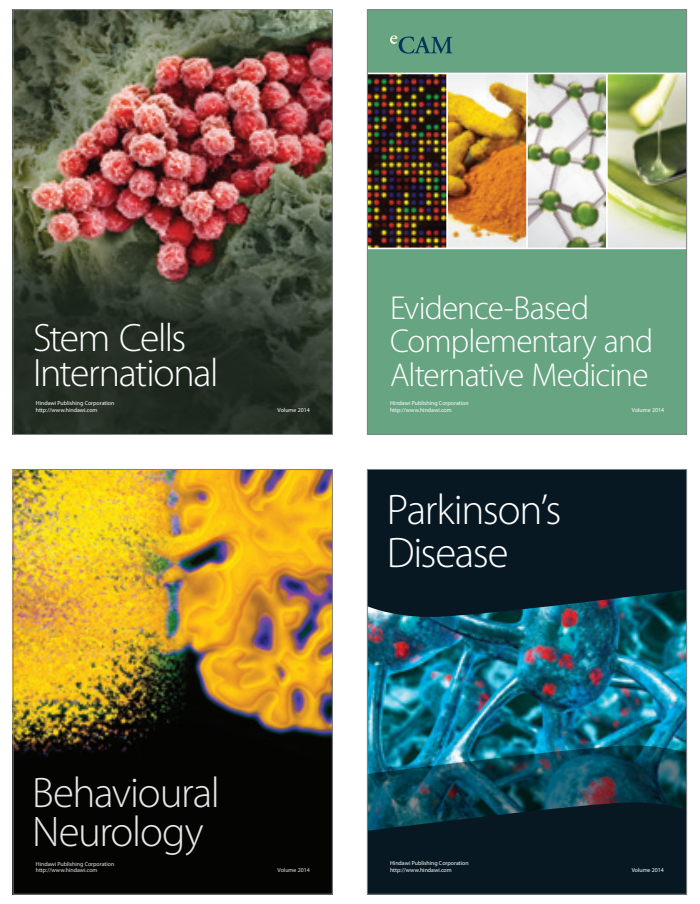
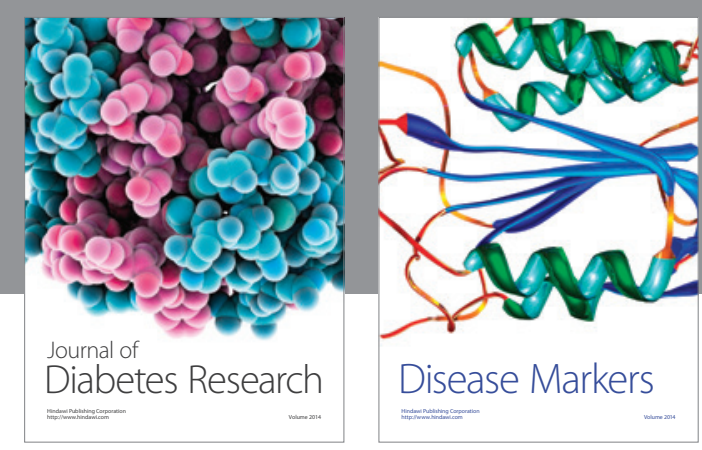

Disease Markers
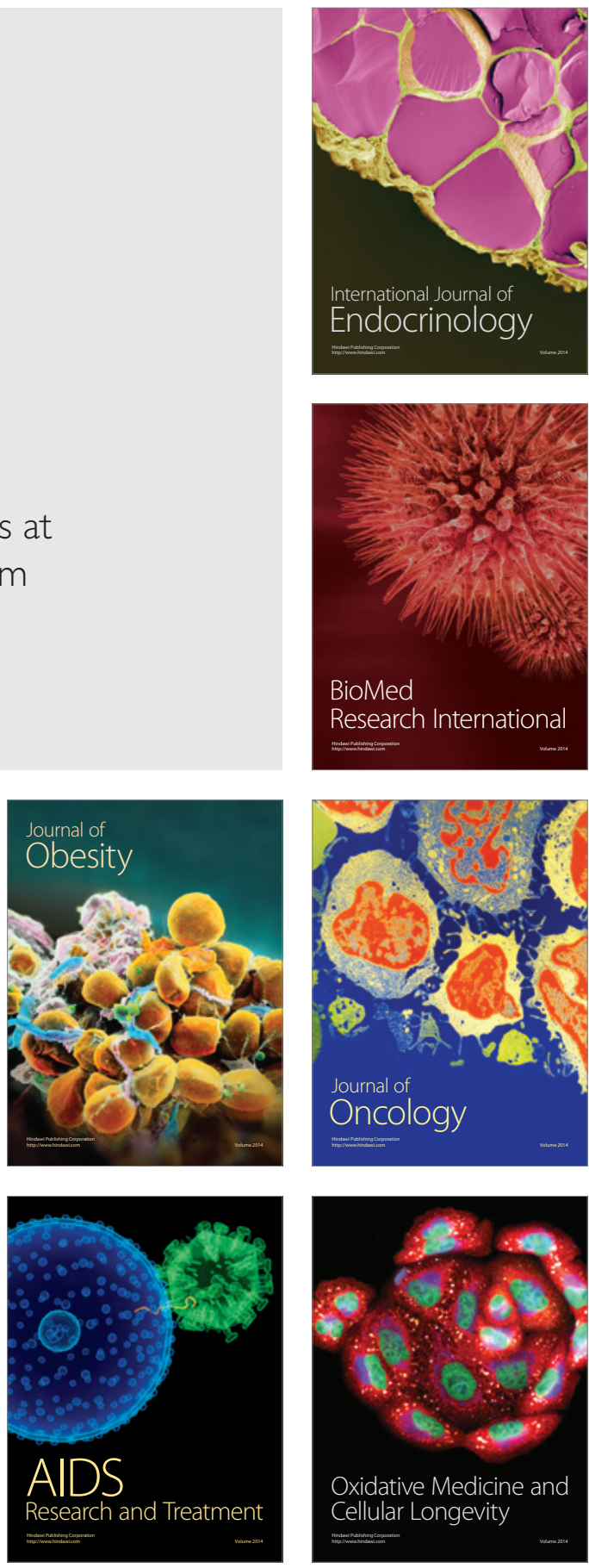